\title{
Metadata Correction: A Virtual Counseling Application Using Artificial Intelligence for Communication Skills Training in Nursing Education: Development Study
}

Shefaly Shorey ${ }^{1}$, PhD; Emily Ang ${ }^{1}$, DNurs; John Yap ${ }^{2}$, MA; Esperanza Debby Ng ${ }^{1}$, BA; Siew Tiang Lau ${ }^{1}$, PhD; Chee Kong $\mathrm{Chui}^{3}, \mathrm{PhD}$

\footnotetext{
${ }^{1}$ Alice Lee Centre for Nursing Studies, National University of Singapore, Singapore, Singapore

${ }^{2}$ Information Techonology, National University of Singapore, Singapore, Singapore

${ }^{3}$ Department of Mechanical Engineering, National University of Singapore, Singapore, Singapore
}

\section{Corresponding Author:}

Shefaly Shorey, $\mathrm{PhD}$

Alice Lee Centre for Nursing Studies

National University of Singapore

Clinical Research Centre 10 Medical Drive

Singapore, 117597

Singapore

Phone: 6566011294

Email:nurssh@nus.edu.sg

\section{Related Article:}

Correction of: https://www.jmir.org/2019/10/e14658

(J Med Internet Res 2019;21(11):e17064) doi: 10.2196/17064

In "A Virtual Counseling Application Using Artificial Intelligence for Communication Skills Training in Nursing Education: Development Study" by Shorey et al (J Med Internet Res 2019;21(10):e14658), the affiliation of authors Shefaly Shorey and Emily Ang has been corrected from "Department of Mechanical Engineering, National University of Singapore" to "Alice Lee Centre for Nursing Studies, National University of Singapore".

The contact information for Shefaly Shorey has also changed from "Department of Mechanical Engineering, National
University of Singapore, Singapore, Singapore" to "Alice Lee Centre for Nursing Studies, National University of Singapore, Clinical Research Centre 10 Medical Drive, Singapore, 117597, Singapore".

The correction will appear in the online version of the paper on the JMIR website on November 26, 2019, together with the publication of this correction notice. Because this was made after submission to PubMed, PubMed Central, and other full-text repositories, the corrected article has also been resubmitted to those repositories.

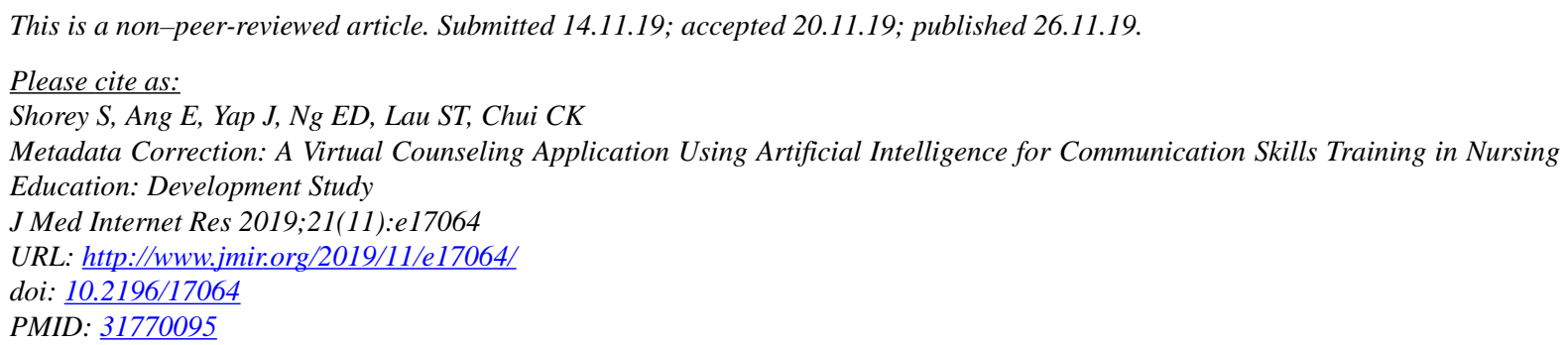

(CShefaly Shorey, Emily Ang, John Yap, Esperanza Debby Ng, Siew Tiang Lau, Chee Kong Chui. Originally published in the Journal of Medical Internet Research (http://www.jmir.org), 26.11.2019. This is an open-access article distributed under the terms of the Creative Commons Attribution License (https://creativecommons.org/licenses/by/4.0/), which permits unrestricted use, distribution, and reproduction in any medium, provided the original work, first published in the Journal of Medical Internet 
Research, is properly cited. The complete bibliographic information, a link to the original publication on http://www.jmir.org/, as well as this copyright and license information must be included. 